\title{
Oral cancer prevention and early detection awareness of Ankara dentists
}

\section{Ăğı kanserinin önlenmesi ve erken teşhisi konusunda Ankara'daki diş hekimlerinin farkındalığı}

\author{
Güzin Neda Hasanoğlu Erbaşar ${ }^{1}$, Cansu Alpaslan² \\ ${ }^{1}$ Ankara Yıldırım Beyazıt Üniversitesi Diş Hekimliği Fakültesi, Ağız, Diş ve Çene Cerrahisi Ana Bilim Dalı, \\ Ankara \\ ${ }^{2}$ Gazi Üniversitesi Diş Hekimliği Fakültesi, Ağız, Diş ve Çene Cerrahisi Ana Bilim Dalı, Ankara
}

\begin{abstract}
ÖZET
GİRIŞ ve AMAÇ: Tüm dünyada diş hekimlerinin ağız kanserine ilişkin farkındalığına ve tutumlarına yönelik çeşitli anket çalışmalarının yürütülmüş olmasına rağmen, Türkiye'de günümüze kadar bu konuyla ilgili herhangi bir araştırma yapılmamıștır. Bu anket çalışmasında Ankara'daki diş hekimliği fakültelerinde eğitim gören stajyer diş hekimlerinin, araştırma görevlilerinin ve serbest diş hekimlerinin ağız kanserinin önlenmesi ve erken teşhisi konusundaki bilgilerinin ve farkındalıklarının değerlendirilmesi amaçlanmıştır.

YÖNTEM ve GEREÇLER: Çalışmada katılımcılara Horowitz ve arkadaşları tarafından geliştirilen anket formu Türkçeye çevrilerek uygulanmıştır. Anket formu, katılımcıların ağız kanseri muayenesine ilişkin uygulamalarına ve hastalardaki risk faktörlerinin değerlendirilmesine ve ağız kanseri konusundaki eğitim seviyelerine dair düşüncelerine yönelik sorulardan oluşmuştur. Elde edilen veriler, lisanslı SPSS 11,5 istatistiksel veri analiz programına aktarılarak değerlendirilmiştir. İstatistiksel anlamlılık için $\mathrm{p}$ değeri $<0.05$ olarak kabul edilmiştir. BULGULAR: Çalışmaya 118 'i stajyer diş hekimi, 145 'i araştırma görevlisi, 74 'ü serbest diş hekimi toplam 337 katılımcı dahil edilmiştir. Çalışmadan elde edilen veriler incelendiğinde Ankara'daki diş hekimlerinin 40 yaş üzerindeki hastalara ağız kanseri muayenesi yapma oranının oldukça düşük olduğu; hastaların tıbbi anamnezini alırken ağız kanseri için risk oluşturan faktörleri değerlendirdikleri ancak risk oluşturmayan faktörler konusunda bilgi yetersizlikleri bulunduğu görülmüştür. Ayrıca diş hekimlerinin yaklaşık yarısı ağız kanseri konusunda aldıkları üniversite eğitimini de zayıf bulmaktadır.

TARTIŞMA ve SONUÇ: Diş hekimleri ağız kanseri muayenesi yapmaları için teşvik edilmeli ve hekimlerin konuyla ilgili eksikliklerini gidermek için demonstrasyon şeklinde eğitim etkinlikleri hazırlanmalıdır. Ayrıca hem lisans düzeyinde hem de sürekli eğitim etkinlikleri çerçevesinde ağız kanseri risk faktörlerini belirleme ve ortadan kaldırma konusunda diş hekimlerinin hastalarına hizmet sunabilecek eğitimi almaları için gerekli düzenlemeler yapılmalıdır.
\end{abstract}

Anahtar Kelimeler: ağız kanseri, erken teşhis, önleme, farkındalık, anket

\begin{abstract}
INTRODUCTION: Several surveys have been cunducted all over the world to evaluate dentists' awareness and behaviors towards oral cancer, but there is no study that assesses the Turkish dentists' awareness related to oral cancers. The aim of this survey was to investigate the knowledge and awareness of trainee dentists, research assistants and general dental practitioners in Ankara regarding prevention and early detection of oral cancer.

METHODS: Turkish translation of the questionnaire that developed by Horowitz and colleagues was used in this study. This questionnaire was designated to evaluate dentists' practices about oral cancer, the screening for risk factors in patients and opinions about their education in oral cancer. Statistical analysis of obtained data was carried out with the use of the SPSS 11.5 for Windows. The significance level was determined as $\mathrm{p}<0.05$.

RESULTS: A total of 337 participants included to the survey; 118 of those were trainee dentists, 145 were research assistants, and 74 were general dental practitioners. When the data were examined; the frequency of oral cancer examination in age of 40 and above was found very low by Ankara dentists, it was also identified that they were proficient in assessing the risk factors for oral cancer when taking a medical history of their patient but their knowledge about non-risk factors showed deficiencies. Besides approximately half of the participants rated their undergraduate training as poor.
\end{abstract}


DISCUSSION AND CONCLUSION: Dentists should be encouraged to perform oral cancer examination and demonstration based courses should be arranged to overcome their deficiencies related to oral cancer. Moreover, necessary regulations as a part of both undergraduate training and continuing education programs about detection and prevention of the oral cancer risk factors should be carried out in order to dentists can provide these services to their patients.

Keywords: oral cancer, early detection, prevention, awareness, questionnaire

\section{Giriş}

Ağız kanseri dudak, dil, ağız tabanı, damak, dişeti, alveoler mukoza, yanak mukozası veya orofarinksi etkileyen kanser türüdür (1). Dünya genelinde her y1419.000'den fazlaağız ve farinks kanseri teşhis edilmekte olup bu malignansiler 240.000'den fazla ölüme yol açmaktadır (2,3). GLOBOCAN'ın son verilerine göre ise 2012 y1lında Türkiye'de 1910 yeni ağız kanseri vakası teşhis edilmiş ve 792 ölüm meydana gelmiştir (4).

Ağız kanseri vakalarının yaklaşık yarısı ile bu kanserlerle ilişkili ölümlerin büyük çoğunluğu 65 yaş ve üstü bireylerde görülmektedir (1). Ancak ağız kanserlerinin gençlerde oluşma eğilimi de her geçen gün artış göstermektedir $(5,6)$. Tütün ve alkol kullanımı ağız kanserinin en önemli risk faktörleri arasında yer almaktadır (1,7). Ayrıca epidemiyolojik ve deneysel araştırmalar insan papilloma virüslerinin (HPV) de ağız kanseri patogenezinde rolü olduğunu göstermiştir.

Ağız kanseri risk faktörlerinin ortaya çıkartılması, hastanın bu konuda bilgilendirilmesi ve özellikle de yüksek risk grubundaki hastalarda ağız kavitesinin periyodik muayenesi diş hekiminin sorumlulukları arasında yer almaktadır. Diş hekimleri malignant ve malignansi olasıllğ olan ağız lezyonlarının teşhisinden sorumlu olmasına rağmen, çeşitli ülkelerde yapılan çalışmalar diş hekimlerinin ve dişhekimliği öğrencilerinin ağız kanserinin önlenmesi ve erken teşhisi ile ilgili prosedürleri düzenli olarak uygulamadıklarını ortaya koymaktadır $(1,8)$. Ağı boşluğu vücudun en kolay ulaşılabilen, herhangi bir cihaz gerektirmeden sadece göz ile muayenesi yapılabilen bir bölgesi olmasına karşın, ağız kanseri yalnızca \%26-48 oranında erken teşhis edilebilmektedir (9).

Elde edilen veriler, lisansli SPSS 11,5 istatistiksel veri analiz programına aktarılarak
Tüm dünyada diş hekimlerinin ağız kanserine ilişkin farkındalığına ve tutumlarına yönelik pek çok anket çalışmasının yürütülmüştür. Fakat Türkiye'de günümüze kadar bu konuyla ilgili herhangi bir araştırma yapılmamıştır. Bu çalışma ile Ankara'daki diş hekimliği fakültelerinde eğitim gören stajyer diş hekimlerinin, araştırma görevlilerinin ve serbest diş hekimlerinin ağız kanserinin önlenmesi ve erken teşhisi konusundaki bilgilerinin ve farkındalıklarının değerlendirilmesi amaçlanmıştır.

\section{Materyal ve Metod}

Çalışmamızda Horowitz ve ark (1) tarafindan geliştirilen anket formu Türkçeye çevrilerek uygulanmıştır. Anket çalışması öncesinde lokal komisyon çalışma onayı alınmıştır. Öncelikle diş hekimlerine anket çalışması hakkında ön bilgi verilmiş; çalışmaya dahil olmayı kabul eden katılımc1lara toplam 38 soru yöneltilmiş ve bu soruların kendilerine en uygun şekilde cevaplandırılması istenilmiştir.

Anket formu, katılımcıların demografik özelliklerine, ağız kanseri muayenesine ilişkin uygulamalarına ve hastalardaki risk faktörlerinin değerlendirilmesine, ağız kanseri lezyonlarının belirti, bulgu ve karakteristikleri hakkındaki bilgilerine ve ağız kanseri konusundaki eğitim seviyelerine dair düşüncelerine yönelik sorulardan oluşmuştur. Katılımcıların görüşlerini ölçebilmek için bazı soruların evet-hayır-bilmiyorum veya kesinlikle katılıyorum-katılıyorum- katılmiyorumkesinlikle katılmıyorum bilmiyorum şeklinde cevaplandırmaları istenmiştir. Son olarak katılımcıların ağız kanseri konusunda sürekli eğitim kurslarına yönelik istekleri ve tercihleri incelenmiştir.

değerlendirilmiştir. İstatistiksel analizde; tanımlayıcı istatistiklerden, frekans/ oran 
dağılımlarından ve değişkenler arasındaki ilişkiyi incelemek için çapraz tablolamalardan yararlanılmıştır.

\section{Sonuçlar}

Çalışmamıza 118'i stajyer diş hekimi, $145^{\prime} \mathrm{i}$ araştırma görevlisi, 74'ü serbest diş hekimi olmak üzere toplam 337 katılımcı dahil edilmiştir (Tablo 1). Katılımcıların haftalık baktıkları ortalama hasta sayıs1 29'dur. Katılımcıların baktığı hastaların ortalama \%79'unun sosyal sağlı sigortas1 bulunmaktadır. Katılımcıların baktığ yaş dağılımına göre oranları; 18-39 yaş arası $\% 41,40-64$ yaş aras1 \%42 ve 65 yaş ve üstü $\% 17$ 'dir.

\section{Hastaların Ağız Kanseri Risk Faktörleri}

\section{Açısından Değerlendirilmesi:}

Katılımciların neredeyse tümü tıbbi anamnez alırken hastanın şu anki tütün kullanımını (\%97,6), ailesinde kanser hikayesinin olup olmadığını $(\% 92,6)$ ve geçmişteki tütün kullanımını (\%92) değerlendirdiğini belirtmiştir. Diş hekimlerinin\%83,3'ününhastaların şu anki alkol kullanımını ve \%71,2'sinin de geçmiş alkol kullanımını dikkate aldığı görülmüştür.

Gerçek risk faktörlerine ilişkin; katılımcıların \%94,1'i tütün ürünlerinin kullanımını, 89,9'u ailedeki kanser geçmişini, \%88,7'si önceki ağız kanseri lezyonlarını, \%78,9'u alkol kullanımını ve \%69,1'i ilerlemiş yaşı doğru şekilde tanımlayabilmiştir. Buna karşın katılımcıların yalnızca \%31,8'i meyve ve sebzelerin az tüketiminin ağız kanseri için risk faktörü olduğunu belirtmiştir (Şekil 1). Risk oluşturmayan faktörler değerlendirildiğinde ise diş hekimlerinin \%84,6's1 obezitenin, \%64,4'ü sıcak yiyecek ve içeceklerin, \%54,6'sı baharatlı yiyeceklerin ağız kanseri için risk oluşturmadığını ifade etmiştir. Katılımcılardan yalnızca \%39,2'si kötü ağız hijyeninin ve \%25,2'si uygunsuz protezlerin ağız kanseri için risk teşkil etmediğini belirtmiştir (Şekil 2).

\section{Ă̆ız Kanseri Muayenesi:}

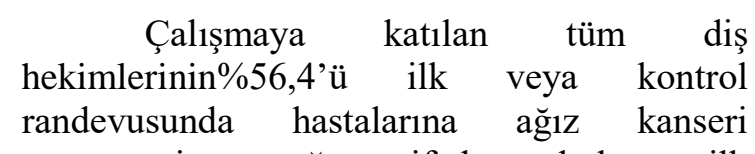
muayenesi yaptığını ifade ederken; ilk randevuda bu muayeneyi yapan hekimlerin oranı $\% 19,9$ 'dur. Katılımcıların \%89,9'u 40 yaş ve üstü hastalara y1lda bir kez ağız kanseri muayenesi yapılması gerektiğini ifade etmiştir. Ancak katılımcıların sadece \%3,3'ünün kırk yaş üstü tüm hastalarına ilk randevuda ağız kanseri muayenesi yaptığı öğrenilmiştir. İlk randevularında 40 yaş üstü hiçbir hastasına ağız kanseri muayenesi yapmayan diş hekimlerinin oran 1 ise $\% 59,1$ 'dir. İk ve kontrol randevularında ağız kanseri muayenesi yapılan hastaların yaş grupları ile belirtilen hekim grupları arasındaki oran dağılımı Şekil 3'te gösterilmiştir. Çalışmamızda dişsiz hastalarına ağız kanseri muayenesi yapan diş hekimlerinin oranı\%19'dur (Şekil 4). Tüm dişsiz hastalarına ilk randevuda ağız kanseri muayenesi yapan katılımcıların oranı ise \%5,3'tür. Çalışmamızda lenf nodu palpasyonu ile ağız kanseri muayenesi yapılan yetişkin hastaların oranı $\% 32,3$ olarak bulunmuş iken 18 yaş üzerindeki tüm hastalarına ilk randevuda lenf bezi muayenesi yapan diş hekimlerinin oranı \%11,6'dır. Katılımcıların \%32,6's1 ise hiçbir hastasına lenf bezi muayenesi yapmadıklarını belirtmiştir.40 yaş üstü hastalara, ağız kanseri muayenesi yapilmama sebebi olarak katılımcıların \%34,4'ü yeterli tekniğe sahip olunmamasını; \%16,9'u ise muayene işleminin çok zaman almasını göstermiştir.

Tüm katılımcılar arasında, geçmiş 12 ay boyunca şüpheli ağız lezyonları için biyopsi yapılan hastaların oranı \%1,5'tir. Katılımcıların $\% 75,7$ 'si geçmiş 12 ay boyunca hiçbir hastasına biyopsi yapmamıştır. Tüm katılımcıların \%97,9'u şüpheli lezyon teşhis ettikleri hastaları uzmanlara yönlendirdiklerini ifade etmişlerdir. Geçmiş 12 aylık zamanda şüpheli oral lezyonların teşhisi için uzmanlara yönlendirilen ortalama hasta sayıs1 2,13'tür.

Katılımcıların ağız kanseri konusunda bilgi düzeylerini ölçmek amaciyla ağız kanserinde erken dönemde ortaya çıkan en yaygın semptomun ne olduğu sorulmuştur. Katılımcıların \%35'i soruyu ülserasyon olarak yanıtlarken, \%34,1'i erken dönem ağız kanseri hastalarının asemptomatik olduğunu ifade etmişlerdir (Tablo 2). 
Diş hekimlerine ağız kanseriyle ilgili aldıkları üniversite eğitimini nasıl değerlendirdikleri sorulduğunda; 2000 y1lından sonra mezun olan diş hekimlerinin $\% 54,4$ 'ü çok iyi ve iyi olarak, \%41,3'ü ise zayıf ve çok zayıf olarak yanıtlamıştır. Aynı soruyu 2000 yılından önce mezun olan diş hekimlerinin \%21,2'si iyi, $\% 69,3$ 'ü ise zayıf ve çok zayıf olarak yanıtlamıştır.

Çalışmamıza katılan diş hekimlerinin \%52,3'ü ağız kanseri muayenesi yapabilecek düzeyde eğitim aldıklarını belirtmiştir. Bu oran öğrencilerde $\% 52,4$, araştırma görevlilerinde $\% 68,5$, serbest diş hekimlerinde ise \%28,3'tür. Tüm katılımciların \%76,8'i ise hastaların boynundaki lenf nodlarınıpalpe edebilecek düzeyde eğitim aldıklarını ifade etmişlerdir.

\section{Ăğı Kanseri Konusunda Sürekli Eğitim İhtiyacı:}

$\mathrm{Bu}$ anket çalışmasında katılımcıların ağız kanserinde sürekli eğitim konusundaki ilgileri de değerlendirilmiştir. Tüm katılımcıların \%63,5'i gelecek dönemlerdeki sürekli eğitim programına ilgileri olduğunu belirtirken, \%18,7'si ise bu eğitimlere ilgi duymadıklarını ifade etmiştir. Sürekli eğitim için demonstrasyon kursları $(\% 23,1)$ ve uzmanlarla konferans görüşmeleri $(\% 20,5)$ en çok tercih edilen yaklaşımlardır.

Ağız kanseri konusunda bir eğitim programına en son ne zaman katıldıkları sorulduğunda diş hekimlerinin $\% 41,5$ 'i şu ana kadar hiçbir ağız kanseri konulu eğitim kursuna katılmadıklarını; \%26,1'i ise geçmiş 12 ayda bu konuyla ilgili bir eğitime katıldığını belirtmiştir (Tablo 3).

\section{Tartışma}

$\mathrm{Bu}$ anket çalışması, ağız kanserinin önlenmesi ve erken teşhisi konusunda diş hekimlerimizin farkındalığını araştıran Türkiye'de yapılmış ilk çalışma olup; elde edilen verilere göre Ankara'daki diş hekimlerinin 40 yaş üzerindeki hastalarına ağız kanseri muayenesi yapma oranının oldukça düşük olduğu; hastaların tıbbi anamnezini alırken ağız kanseri için risk oluşturan faktörleri değerlendirdikleri ancak risk oluşturmayan faktörler konusunda bilgi yetersizliklerinin bulunduğu görülmüştür.
Çalışmamızda Ankara Diş hekimleri Odası aracılı̆̆ ile Ankara'daki diş hekimlerine e-posta yoluyla anket göndererek çok daha fazla sayıda katılımcıya ulaşılması hedeflenmiş olmasına rağmen diş hekimlerinden hiçbir geri dönüş alınamamıştır. Bu nedenle tüm anketlerin el ile dağıtılarak doldurulması sağlanmıştır. Sayısal açıdan yeterli olmasa da bu dağılım Ankara'daki diş hekimlerinin genel eğilimini yansıtabilecek durumdadır. Diğer ülkelerdeki ilgili anket çalışmalarına bakıldığında da benzer sayıda diş hekiminin araştırmalara dahil edildiği görülmektedir $(2,5,7)$.

Diş hekimlerinin ağız kanseri muayenesi ve erken teşhisi konusundaki sorumluluklarının yanı sıra hastalarını risk faktörleri açısından bilgilendirme sorumlulukları da bulunmaktadır. Ancak popülasyonun tamamında ağız kanseri taraması yapmak oldukça pahalı olacağından, taramanın öncelikle yüksek risk grubundaki kişilere yönelik olması önerilmektedir. Bu nedenle, ağız kanseri risk faktörlerinin bilinmesi ve risk grubundaki hastaların belirlenmesi büyük önem taşımaktadır. Araştırmamıza katılan diş hekimlerinin büyük kısmı ağız kanseri için risk oluşturan faktörleri tanımlayabilmiştir. Ancak kötü ağız hijyeni ve uygunsuz protezler gibi risk oluşturmayan faktörler çok daha az sayıda katılımeı tarafından doğru şekilde tanımlanabilmiştir. Farklı ülkelerde gerçekleştirilmiş araştırmalarda da bu sonuçlara paralel olarak; katılımcıların çok büyük yüzdesinin ağız kanseri için risk oluşturan faktörleri doğru şekilde tanımlayabildiği ancak risk oluşturmayan faktörler konusunda yetersiz bilgiye sahip olduğu rapor edilmiştir $(2,10-12)$.

Çalışmamıza katılan diş hekimlerinin\%89,9'u 40 yaş üstü bireylere yılda $1 \mathrm{kez}$ ağız kanseri muayenesi yapılması gerektiğini ifade etmesine rağmen katılımcıların yarısından fazlasının 40 yaş üstü hiçbir hastasına ağız kanseri muayenesi yapmadığını öğrenilmiştir. Bu oran Amerika ve İngiltere genelinde ise $\% 81$ ila 93 arasinda değişmektedir $\quad(1,5,7,13)$. Ayrıca araştırmamızda tüm dişsiz hastalarına ilk randevusunda ağız kanseri muayenesi yapan diş hekimlerinin oranı $\% 5,3$ olarak bulunmuştur. Applebaum ve ark (7) tarafindan Massachusetts'te yapılan araştırmada bu oran \%88 olarak rapor edilmiştir ki bu farklılık oldukça çarpıcı boyuttadır. Çalışmamızda 
izlenen bu düşük muayene oranları; ülkemizdeki diş hekimi başına düşen hasta sayısının İngiltere ve Amerika'dan daha fazla olması (14) ve/veya diş hekimlerinin klinik iş yoğunluğunda ağız kanseri muayenesine zaman ayırmak istememeleri ile açıklanabilir.

Ağız kanseri muayenesinin önemli bir komponentini de lenf bezi muayenesi oluşturmaktadır. Fakat çalışmamızda katılımcıların yalnızca üçte birinin ağız kanseri muayenesi esnasında lenf nodlarını palpe ettiği öğrenilmiştir. Horowitz'in (1) çalışmasında şekilde lenf bezi muayenesinin yapılma oranı \%35 civarında rapor edilmiştir. Diş hekimlerinin lisans düzeyinde konuyla ilgili aldıkları eğitimin eksik olması, bilgilerini sürekli eğitim programlarıla güncel tutmamaları ve/veya ağız kanseri muayenesinde yeterli tekniğe sahip olmamaları lenf bezi muayenesinin yapilmama sebepleri arasında gösterilebilir. $\mathrm{Bu}$ bilgilerle örtüşecek şekilde Ankara'daki diş hekimlerinin yalnızca \%52,3'ü ağız kanseri muayenesi yapabilecek düzeyde eğitim aldıklarını düşünmektedir. Özellikle serbest diş hekimleri bu konuda yetersiz olduklarını belirtmektedir. Mezuniyet yılı esas alınarak incelendiğinde ise; 2000 y1lından önce mezun olan diş hekimlerinin büyük çoğunluğunun ağı kanseri muayenesi konusunda üniversitede aldıkları eğitimi zayıf buldukları görülmüştür. İngiltere'de yapılan benzer araştırmada da pratisyen diş hekimlerinin \%41'i ağız kanserinin tanınması konusunda mezuniyet öncesi derslerin yetersiz olduğunu ifade etmiştir (5). Diş hekimlerinin mezuniyet sonrasında düzenli olarak ihtiyaç duydukları alanlarda çeşitli eğitim etkinliklerinde yer almaları, bilgilerini güncellemeleri ve profesyonel gelişimlerine katkı sağlamaları bu meslek için zorunludur. Çalışmamıza dahil olan diş hekimlerinin \%41,5'i mezuniyet sonrasında ağız kanseri konusunda herhangi bir eğitim faaliyetinde yer almadıklarını bildirmişlerdir. Bununla birlikte katılımciların \%60'dan fazlası bu konudaki sürekli eğitim programlarına ilgi duyduğunu da ifade etmiştir. New York eyaletinde bir yönetmelikle tüm diş hekimlerinin sürekli eğitimin bir parçası olarak en az 2 saat ağız kanserinin önlenmesi ve erken tanısı konusunda eğitim almaları zorunlu tutulmaktadır (15). Eğitim faaliyetleri yanında, farkındalık kampanyaları da hem kamuoyu hem de diş hekimleri tarafından ağız kanserine gereken önemin verilmesini sağlayacaktır. Amerika Birleşik Devletleri'nde Amerikan Diş Hekimleri Derneği ve CDx Laboratuarları birlikte ağız kanserinin erken teşhisinin önemini vurgulamak için ulusal düzeyde ağız kanseri farkındalık kampanyası yapmışlardır. Diş hekimlerinin $\% 25$ 'i bu kampanyadan sonra ağız lezyonlarına daha fazla dikkat ettiklerini, \%39,6's1 hastalarına ağız kanseri konusunda bilgi verdiklerini, \%8,6's1 son 6 ayda daha fazla lezyon teşhis ettiklerini bildirmişlerdir (16).

Ülkemizde üniversitelerin ve meslek kuruluşlarının, ağız kanseri konusunda diş hekimlerinin isteklerini karşılayacak biçimde yaygın eğitim etkinlikleri sunmaları ve hekimleri eksikliklerini gidermek için bu programlara katılmaları hususunda teşvik etmeleri gerekmektedir. Ayrıca gerek lisans düzeyinde gerekse sürekli eğitim programları çerçevesinde diş hekimlerinin ağız kanseri risk faktörlerini belirleme ve ortadan kaldırma konusunda hastalarına hizmet sunabilecek eğitimi almaları için gereken düzenlemelerin yapılması önem taşımaktadır. Ağız kanseri ile ilişkili mortalite ve morbidite oranlarının ancak iyi eğitimli ve bilgili diş hekimleri ile azaltılabileceği unutulmamalıdır. 
Tablo 1: Katılımcıların demografik özellikleri

\begin{tabular}{|l|l|}
\hline Cinsiyet & \\
\hline Erkek & $\% 45,5$ \\
\hline Kadın & $\% 54,5$ \\
\hline Mezuniyet Zamanı & \\
\hline 2000 yılından önce & $\% 25,5$ \\
\hline 2000 yılından sonra & $\% 74,5$ \\
\hline Çalışma şekli & \\
\hline Stajyer Öğrenci & $\% 35$ \\
\hline Araştırma Görevlisi & $\% 43$ \\
\hline Serbest Diş hekimi & $\% 22$ \\
\hline
\end{tabular}

Tablo 2: Ağız kanserinin erken dönemde en yaygın izlenen semptomlarına katılımcılar tarafından verilen cevapların dağılımı

\begin{tabular}{|l|l|l|l|}
\hline & $\begin{array}{l}\text { Stajyer Diş hekimleri } \\
(\boldsymbol{\%})\end{array}$ & $\begin{array}{l}\text { Araştırma Görevlileri } \\
(\boldsymbol{\%})\end{array}$ & $\begin{array}{l}\text { Serbest Diş hekimleri } \\
(\boldsymbol{\%})\end{array}$ \\
\hline Ağrı & 14,4 & 4,8 & 4 \\
\hline Ülserasyon & 32,2 & 38,6 & 32,4 \\
\hline Şişlik & 2,5 & 14,4 & 27 \\
\hline Asemptomatik & 35,6 & 35,8 & 28,3 \\
\hline Bilmiyorum & 2,5 & 6,2 & 8,1 \\
\hline
\end{tabular}

Tablo 3.Çalışmaya dahil olan diş hekimlerinin ağız kanseri konusunda bir eğitim etkinliğine katılma oranları

\begin{tabular}{|l|l|}
\hline Geçen yıl & $\mathbf{\% 2 6 , 1}$ \\
\hline $2-5$ yıl önce & $\mathbf{\% 1 4 , 8}$ \\
\hline 5 yıldan daha önce & $\mathbf{\% 3 , 6}$ \\
\hline Hiçbir zaman katılmayanlar & $\mathbf{\% 4 1 , 6}$ \\
\hline
\end{tabular}




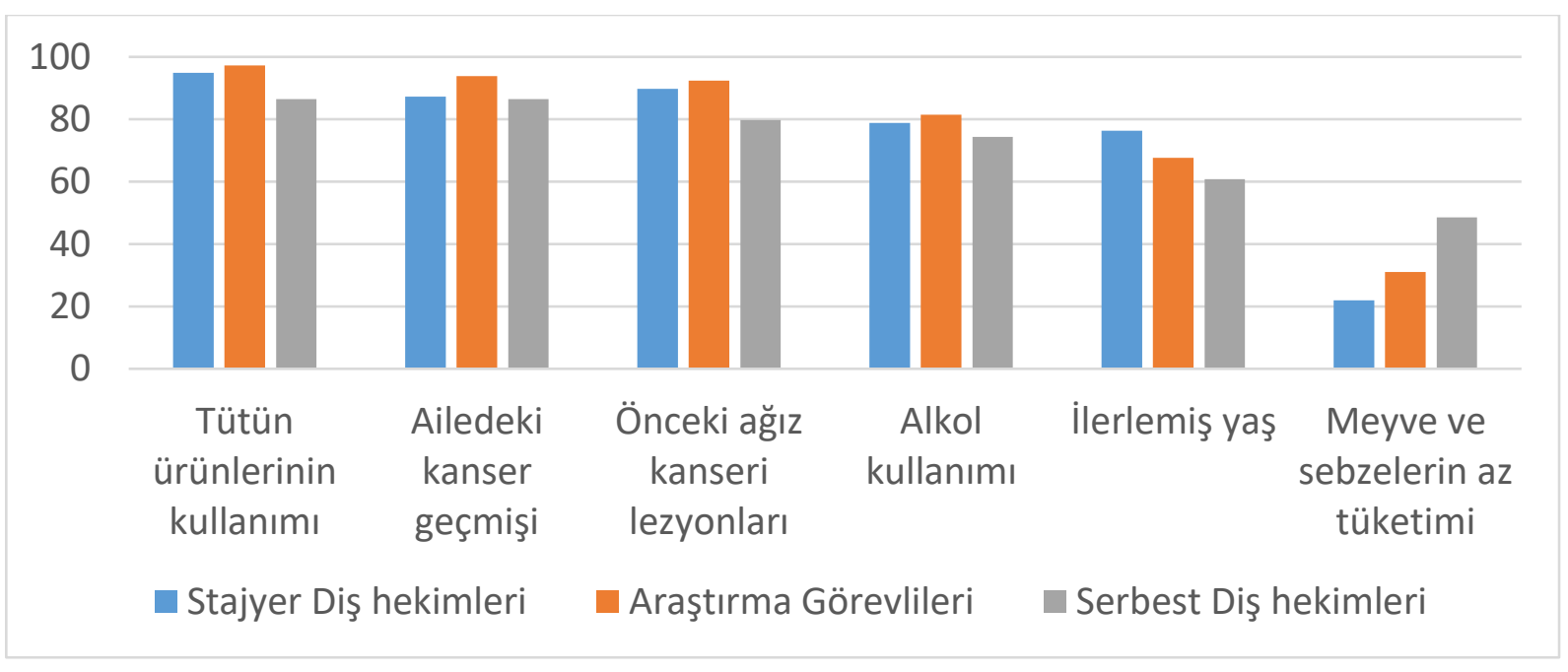

Şekil 1: Katılımcıların ağız kanserinde gerçek risk oluşturan faktörlere yönelik bilgi seviyesi

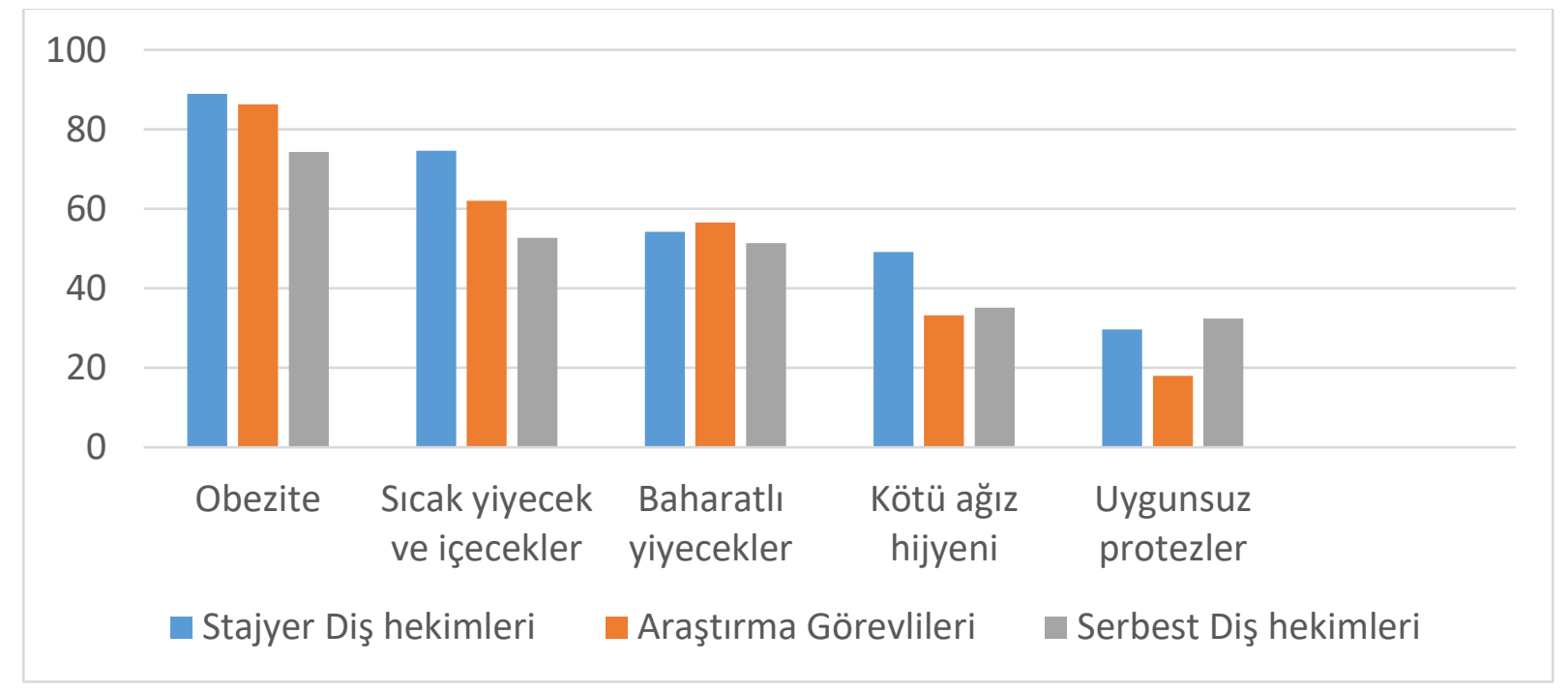

Şekil 2: Katılımcıların ağız kanserinde risk oluşturmayan faktörlere yönelik bilgi seviyesi 


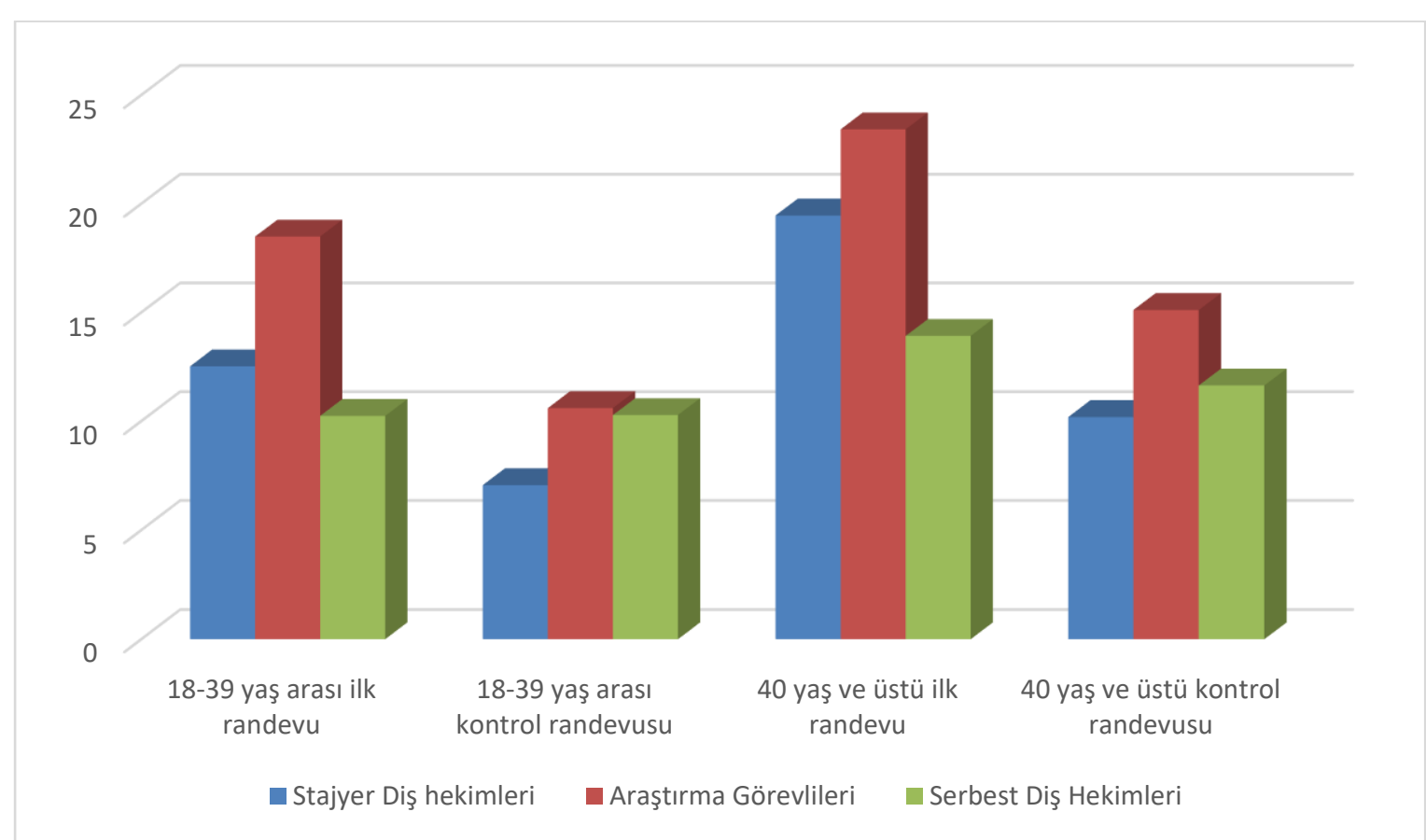

Şekil 3.Belirtilen yaş gruplarında ilk ve kontrol randevularında ağız kanseri muayenesi yapılan ortalama hasta yüzdeleri

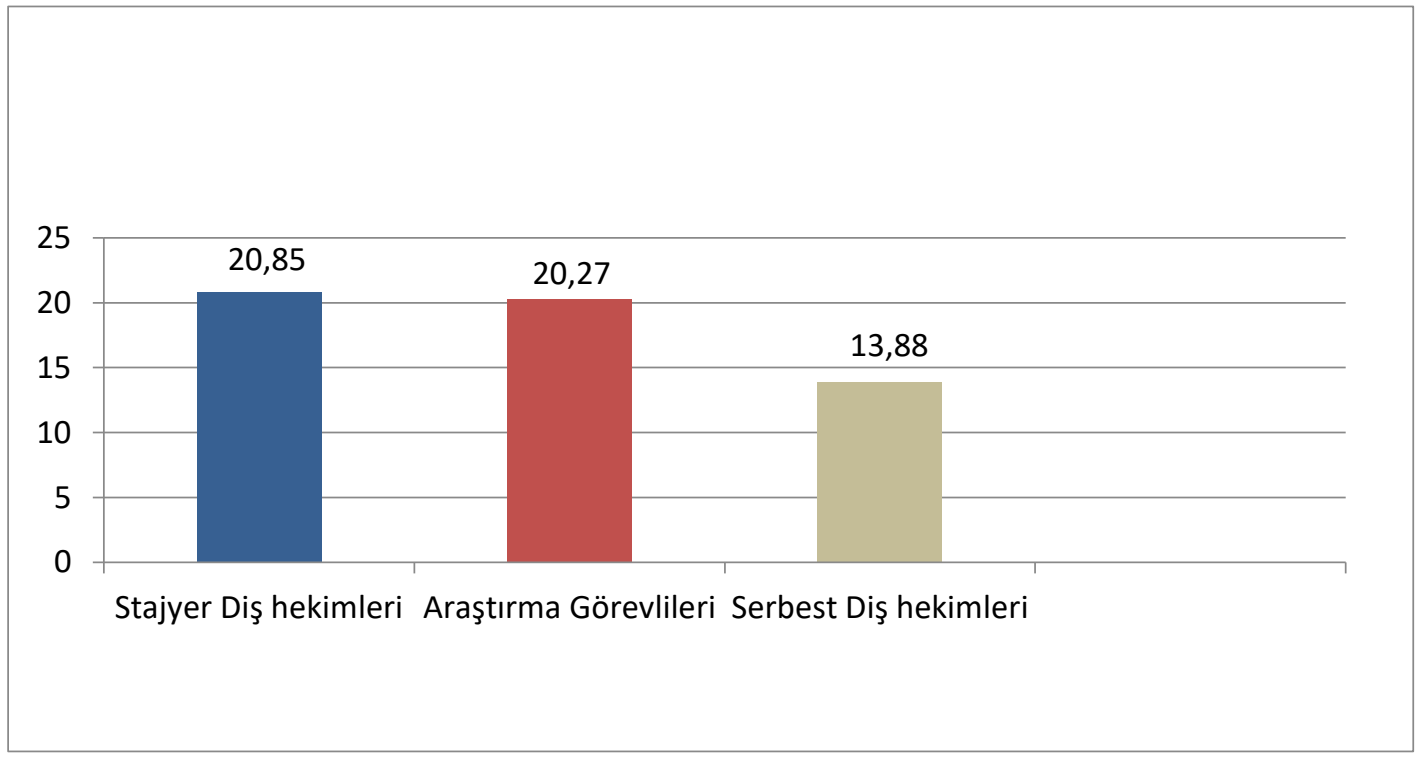

Şekil 4. Ağız kanseri muayenesi yapılan dişsiz hastaların oranı

\section{Referanslar}

1. Horowitz AM, Drury TF, Goodman HS, Yellowitz JA. Oral pharyngeal cancer prevention and early detection. Dentists' opinions and practices. J Am Dent Assoc 2000;131(4):453-62.

2. Razavi SM, Zolfaghari B, Foroohandeh M, Doost ME, Tahani B. Dentists' knowledge, attitude, and practice regarding oral cancer in Iran. J Cancer Educ 2013;28(2):335-41.

3. Ferlay J, Soerjomataram I, Dikshit R, et al. Cancer incidence and mortality worldwide: sources, methods and major patterns in GLOBOCAN 2012. Int J Cancer 2015;136(5):E359-86.

Adress for correspondence: Yard. Doç. Dr. Güzin Neda Hasanoğlu Erbaşar, Dögol Cd. İncitası Sk. MEB Kampüsü H Blok Besevler 06560 Ankara - Türkiye e-mail: neda986@gmail.com

Available at www.actaoncologicaturcica.com

Copyright $\mathbb{C}$ Ankara Onkoloji Hastanesi 
4. http://globocan.iarc.fr/Pages/burden_sel.aspx .

5. Kujan O, Duxbury AJ, Glenny AM, Thakker NS, Sloan P. Opinions and attitudes of the UK's GDPs and specialists in oral surgery, oral medicine and surgical dentistry on oral cancer screening. Oral Dis 2006;12(2):194-9.

6. Greenlee RT, Hill-Harmon MB, Murray T, Thun M. Cancer statistics, 2001. CA Cancer J Clin 2001;51(1):15-36

7. Applebaum E, Ruhlen TN, Kronenberg FR, Hayes C, Peters ES. Oral cancer knowledge, attitudes and practices: a survey of dentists and primary care physicians in Massachusetts. J Am Dent Assoc 2009;140(4):461-7.

8. Carter LM, Ogden GR. Oral cancer awareness of general medical and general dental practitioners. Br Dent J 2007;203(5):E10; discussion 248-9.

9. Pitiphat W, Diehl SR, Laskaris G, et al. Factors associated with delay in the diagnosis of oral cancer. J Dent Res 2002;81(3):192-7.

10. Yellowitz JA, Horowitz AM, Drury TF, Goodman HS. Survey of U.S. dentists' knowledge and opinions about oral pharyngeal cancer. J Am Dent Assoc 2000;131(5):653-61.

11. Clovis JB, Horowitz AM, Poel DH. Oral and pharyngeal cancer: knowledge and opinions of dentists in British Columbia and Nova Scotia. J Can Dent Assoc 2002;68(7):415-20.

12. Hertrampf K, Wiltfang J, Koller M, Klosa K, Wenz HJ. Dentists' perspectives on oral cancer: a survey in Northern Germany and a comparison with international data. Eur $\mathbf{J}$ Cancer Prev 2010;19(2):144-52.

13. Gajendra S, Cruz GD, Kumar JV. Oral cancer prevention and early detection: knowledge, practices, and opinions of oral health care providers in New York State. J Cancer Educ 2006;21(3):15762.

14. http://www.tdb.org.tr/tdb/v2/basin_icerik.php?y er_id $=5 \& i d=15$.

15. http://nysdflearning.org/courses.html.

16. Stahl S, Meskin LH, Brown LJ. The American Dental Association's oral cancer campaign: the impact on consumers and dentists. J Am Dent Assoc 2004;135(9):1261-7. 